Оригинальная статья/Original article

УДК 612.041.1+621.3

DOI: http://doi.org/10.20914/2310-1202-2017-3-26-30

Исследование реологических и теплофизических характеристик крови крупного рогатого скота

Сергей Т. Антипов
Виталий Ю. Овсянников 1 ast@vsuet.ru
Александр А. Корчинский 1
Ключевые слова: кровь, вязкость, теплофизические характеристики

\title{
Investigation of rheological and thermophysical characteristics blood of cattle
}

\begin{tabular}{lll}
\hline \hline Sergei T. Antipov & 1 & ast@vsuet.ru \\
Vitaly Yu. Owsyannikov & 1 & ows2003@mail.ru \\
Aleksandr A. Korchinskij & 1 & 79192492267@ya.ru \\
Aleksandr A. Smyrnykh & 1 & ucheba-a.a.smirnykh@mail.ru \\
\hline
\end{tabular}

$\overline{1}$ Voronezh state university of engineering technologies, Revolution Av., 19 Voronezh, 394036, Russia

Summary. Perfection of machinery and technology aimed at the complex non-waste processing of the secondary raw materials of the meat industry is an urgent task. The blood of cattle, which is the most valuable raw material for the production of medicines, as well as a number of food products enriched with compounds of the protein-hemoglobin complex. The rheological behavior of the processing object is of great importance in the physicomechanical action on the part of the working bodies, in the movement of liquid media through technological pipelines, and also in cases of intensification of heat exchange processes. The rheological behavior of blood of cattle was studied depending on the temperature and the content of dry substances in it, and the thixotropic properties were analyzed. It is shown that as the temperature decreases and the water content decreases, the viscosity of the blood increases due to the aggregation of its constituents, which determines the non-Newtonian behavior of the blood. Knowledge of thermophysical characteristics of blood cattle is necessary for optimization and control of technological processes of its processing and concentration. At the same time, the inverse problem also plays a role: the development of methods for predicting properties in order to obtain a final product with predetermined thermophysical characteristics. The absence of reliable values of the thermophysical characteristics of blood of cattle was experimentally investigated: the thermal conductivity, thermal diffusivity, density and specific heat of blood, depending on the temperature and the content of dry soluble substances. It was revealed that the dependence of the coefficients of heat and thermal diffusivity of blood on temperature have the form of smooth curves monotonically increasing with increasing temperature.

Keywords: blood, viscosity, thermophysical characteristics

Для цитирования

Антипов С.Т., Овсянников В.Ю., Корчинский А.А., Смирных А.А Исследование реологических и теплофизических характеристик крови крупного рогатого скота // Вестник ВГУИТ. 2017. Т. 79. № 3. C. 26-30. doi:10.20914/2310-1202-2017-3-26-30
For citation

Antipov S.T., Ovsjannikov V.Ju., Korchinskij A.A., Smirnyh A.A. Investigation of rheological and thermophysical characteristics blood of cattle. Vestnik VGUIT [Proceedings of VSUET]. 2017. vol. 79. no. 3. pp. 26-30. (in Russian). doi:10.20914/2310-1202-2017-3-26-30 


\section{Введение}

Выбор рациональных технологических параметров переработки и концентрирования крови крупного рогатого скота (КРС) должен базироваться на изучении изменений ее свойств при механическом и температурном воздействии на продукт при обработке в рабочем объеме аппарата $[1,2]$.

Определяющее влияние на характеристики процесса переработки и концентрирования крови, а также качество получаемого продукта оказывают реологические свойства, зависящие от таких показателей качества, как химический состав, содержание влаги, температура и др.

Плотность крови - важнейшая физическая характеристика, отражающая значение массы единицы объема вещества и широко использующаяся в расчетных и модельных зависимостях при расчете и проектировании технологического оборудования.

Эффективная вязкость крови КРС является важной реологической характеристикой. В жидких средах вязкость обусловлена, как правило, межмолекулярным взаимодействием, ограничивающим подвижность молекул. При этом вязкость напрямую зависит от химической структуры и состава молекул, входящих в состав раствора.

Знание теплофизических характеристик крови КРС необходимо для оптимизации и контроля технологических процессов ее переработки и концентрирования.

Вместе с тем играет роль и обратная задача - разработка способов прогнозирования свойств с целью получения конечного продукта с заранее заданными теплофизическими характеристиками.

\section{Материалы и методы исследования}

Плотность крови КРС исследовали ареометрическим методом при помощи лабораторного ареометра АНТ-2. Величину плотности рассчитывали как среднее арифметическое между двумя пробами.

Зависимость плотности крови и сконцентрированной крови КРС от температуры и содержания сухих веществ в ней представлена на рисунке 1.

Исследовали изменение эффективной вязкости крови КРС в зависимости от температуры и содержания сухих веществ при помощи вибровискозиметра SV-10, принцип действия, которого основан на зависимости мощности, затрачиваемой на возбуждение вибрации двух тонких сенсорных пластин с частотой 30 Гц и постоянной амплитудой около 1 мм, от вязкости жидкости. Указанный принцип, реализованный в приборе, позволяет проводить измерения во всем диапазоне без замены сенсорных пластин. Вибровискозиметр SV-10 включает в свой состав измерительный блок и блок управления с цифровым дисплеем. В приборе размещен датчик температуры, позволяющий измерить температуру исследуемого образца в любой момент времени.

Изменение эффективной вязкости крови и концентрата крови КРС в зависимости от температуры и содержания сухих веществ представлено на рисунке 2.

Методом ротационной вискозиметрии исследовали тиксотропность объекта исследования. Эксперименты проводили в диапазоне скорости сдвига 48,6-1312 $\mathrm{c}^{-1}$ на ротационном вискозиметре «Реотест-2». По результатам экспериментов строили графики зависимостей касательного напряжения от скорости сдвига (рисунок 3).

Исследование теплоемкости крови КРС осуществляли при помощи измерителя теплоемкости ИТ-С-400, с измерительным блоком, основой которого является С- калориметр, оснащенный блоком питания и регулирования, обеспечивающий монотонный режим нагрева со средней скоростью $0,1^{\circ} \mathrm{C} /$ мин и автоматическое регулирование температуры адиабатной оболочки.

Принцип измерения теплоемкости основан на использовании метода равномерного нагрева образца в условиях максимально приближенных к отсутствию теплообмена с окружающей средой. Поток теплоты от нагревателя передавался ампуле с образцом крови КРС. Адиабатическая оболочка с нагревателем обеспечивала барьер, предотвращающий теплообмен образца крови с окружающей средой.

В течение эксперимента осуществляли увеличение температуры основания образца по линейному закону за счет регулировки электрических характеристик нагревателя прибора. Температуры адиабатической оболочки и ампулы с образцом крови КРС поддерживали постоянными посредством управления. Удельную теплоемкость образца определяли косвенно, на основании времени запаздывания изменения температур между верхним и нижним регистратором температур, с учетом объема исследуемой крови и постоянным величинам прибора.

Для определения коэффициента теплопроводности использовали метод регулярного теплового режима, который осуществлялся при помощи шарового бикалориметра. Измерительная установка содержала два термостатов, заполненных водой и снабженных контактными термометрами для контроля и регулирования. Шаровой 
бикалориметр состоит из внутреннего шара, изготовленного из меди и оболочки, в пространство между которыми через патрубки заливалась кровь КРС. Внутри шара и в термостатируюмой жидкости размещались темопары, подключенные к измерительному прибору, в качестве которого использовался измеритель - регулятор ТРМ138 компании «Овен».

Перед началом измерений бикалориметр с образцом крови КРС подвергался термостатированию до заданной температуры измерения в термостате. Затем осуществлялся, быстрый перенос образца исследуемой крови КРС в измерительную ячейку калориметра и измерение коэффициента теплопроводности крови КРС.

Используя экспериментальные данные были построены графики зависимостей теплофизических характеристик крови КРС при различных содержаниях сухих веществ и температурах (рисунки 4-7).

\section{Результаты и их обсуждение}

Графики зависимости изменения плотности крови и сконцентрированной крови КРС носят нелинейный характер. С повышением температуры исследуемого вещества его плотность монотонно снижается.

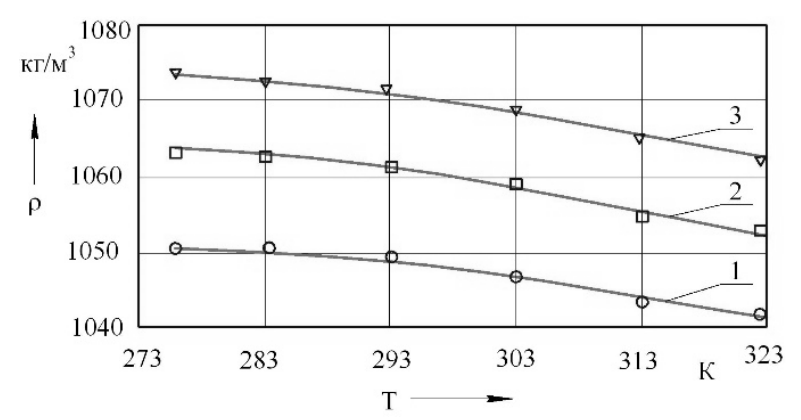

Рисунок 1. Изменение плотности крови и сконцентрированной крови КРС от температуры, К и содержания сухих веществ, \%: 1 - 19,0; 2 - 26,4; 3 - 37,1

Figure 1. Change in blood density and concentrated blood of cattle as a function of temperature, $\mathrm{K}$ and content of solids, \%: 1 - 19.0; 2 - 26.4; $3-37.1$

Важнейшими факторами, оказывающими характерное влияние на вязкость крови выступают свойства плазмы, гематокрит, агрегация и деформируемость клеточных структур. При этом следует отметить, что подавляющее количество эритроцитов в крови, по сравнению с лейкоцитами и тромбоцитами, в основном определяются красными кровяными клетками, и, в частности, объемной концентрацией эритроцитов (содержанием и средним объемом), называемым гематокритом. Гематокрит, выделяемый из пробы крови при разделении центрифугированием, составляет, как правило, 0,4-0,5 дм $3 /$ дм $^{3}$ [3]

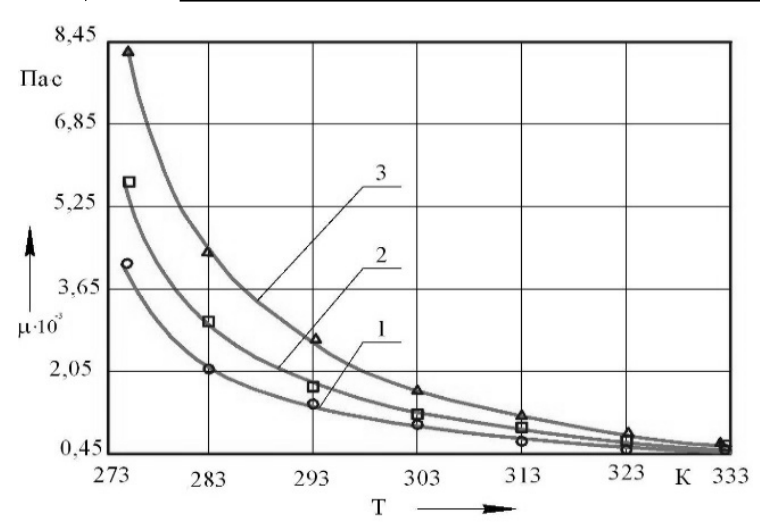

Рисунок 2. Изменение эффективной вязкости крови и сконцентрированной крови КРС в зависимости от температуры, К и содержания сухих веществ, \%: 1 19,0; 2 - 26,4; 3 - 37,1

Figure 2. Change in effective viscosity blood and concentrated blood of cattle in temperature, $\mathrm{K}$, and content of dry substances, \%: 1 - 19.0; 2 - 26.4; 3 - 37.1

Анализ полученных зависимостей позволяет заключить, что при понижении температуры и снижении содержания воды вязкость крови увеличивается за счет агрегации ее составляющих, что определяет неньютоновское поведение крови. Это свойство обусловлено агрегационной способностью эритроцитов, причем физиологическая агрегация эритроцитов является обратимым процессом. При этом известное свойство эритроцитов формировать агрегаты зависит от гемодинамических, плазменных, электростатических, механических и многих других факторов [4].

В настоящее время предложен ряд теорий, характеризующих механизм агрегации эритроцитов. Наиболее популярная теория мостикового механизма объясняет характер формирования эритроцитов исходя из адсорбционного взаимодействия фибриногена и крупных белковых молекул, в частности Y-глобулинов, которые при уменышении сдвиговых сил обеспечивают агрегацию эритроцитов и, соответствующее изменение вязкости крови.

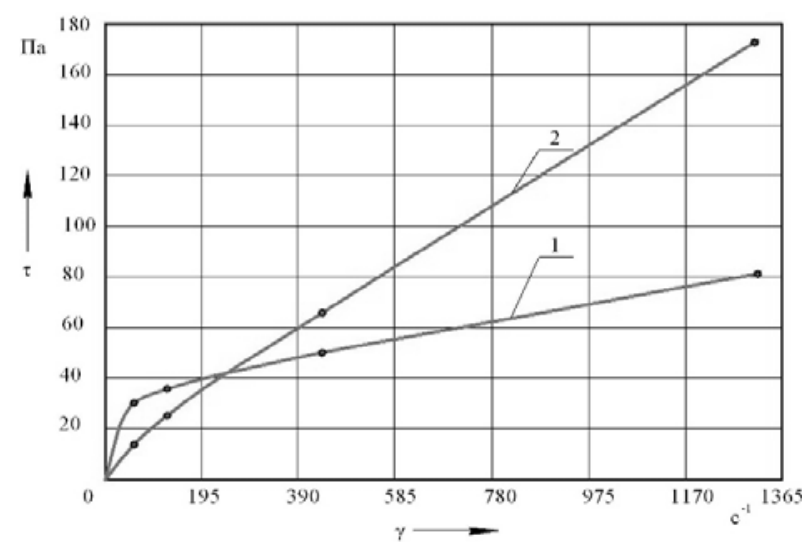

Рисунок 3. Тиксотропные свойства крови КРС при содержании сухих веществ, \%: 1 - 19,0; 2 - 26,4

Figure 3. Thixotropic properties of blood cattle at the content of solids, \%: 1 - 19.0; 2 - 26.4 
Из анализа графиков, представленных на рисунке 3 можно сделать вывод, что кровь и сконцентрированную кровь КРС можно отнести к неньютоновским твердообразным сплошным средам, которые характеризуются при течении как упруго-вязко-пластичные.

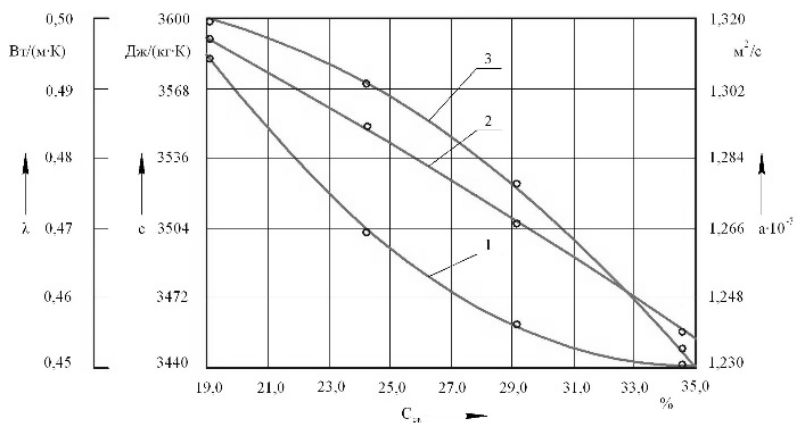

Рисунок 4. Изменение теплофизических свойств крови КРС в зависимости от содержания сухих веществ $\mathrm{C}_{\mathrm{cB}}$ \% \% при температуре 278 К: 1 - удельной теплоемкости с, Дж/(кг×К); 2 - коэффициента теплопроводности $\lambda$, Вт/(м/К); 3 - коэффициента температуропроводности а, $\mathrm{m}^{2} / \mathrm{c}$

Figure 4 . The change in the thermophysical properties of the blood of cattle as a function of the dry matter content of $\mathrm{C}_{\mathrm{sv}}$, \% at a temperature of $278 \mathrm{~K}: 1$ - specific heat c, $\mathrm{J} /(\mathrm{kg} \times \mathrm{K}) ; 2-$ coefficient of thermal conductivity $\lambda$, $\mathrm{W} /(\mathrm{m} / \mathrm{K}) ; 3$ - coefficient of thermal diffusivity a, $\mathrm{m}^{2} / \mathrm{s}$

Коэффициент теплопроводности $\lambda$ характеризует теплопроводящие свойства крови КРС и в отличие от теплоемкости не является аддитивной функцией, поскольку зависит не только от химического состава, но и от строения вещества, а также от направления теплового потока. Коэффициент теплопроводности крови КРС и ее компонентов характеризует их теплоинерционные свойства и интенсивность способности нагреваться или охлаждаться.

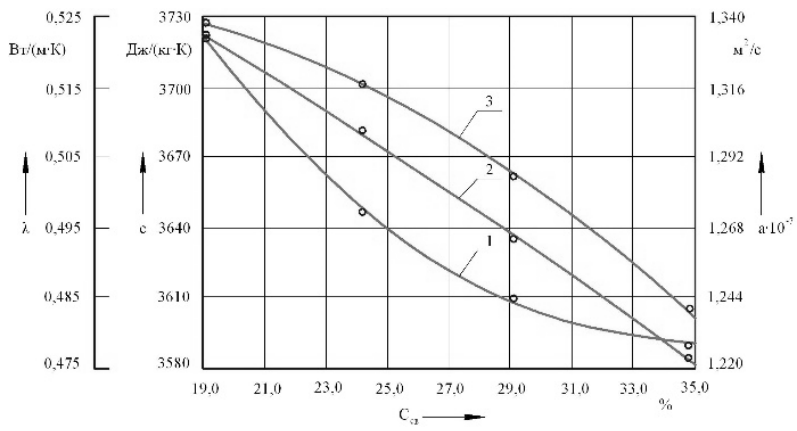

Рисунок 5. Изменение теплофизических свойств крови КРС в зависимости от содержания сухих веществ $\mathrm{C}_{\mathrm{c}}$, $\%$ при температуре $\mathrm{T}=293 \mathrm{~K}: 1-$ удельной теплоемкости $\mathrm{c}, \quad$ Дж/(кг×К); 2 - коэффициента теплопроводности $\lambda, \mathrm{BT} /(\mathrm{M} / \mathrm{K}) ; 3-\quad$ коэффициента температуропроводности $\mathrm{a}, \mathrm{M}^{2} / \mathrm{c}$

Figure 5. The change in the thermophysical properties of blood in cattle as a function of the dry matter content of $\mathrm{C}_{\mathrm{sv}}, \%$ at a temperature of $\mathrm{T}=293 \mathrm{~K}: 1-$ specific heat $\mathrm{c}$, $\mathrm{J} /(\mathrm{kg} \times \mathrm{K}) ; 2-$ coefficient of thermal conductivity $\lambda$, $\mathrm{W} /(\mathrm{m} / \mathrm{K}) ; 3$ - coefficient of thermal diffusivity a, $\mathrm{m}^{2} / \mathrm{s}$

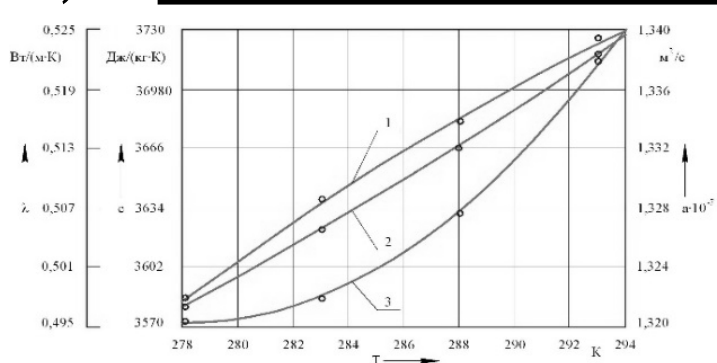

Рисунок 6. Изменение теплофизических свойсв крови КРС в зависимости от температуры, К при содержании сухих веществ $\mathrm{C}_{\mathrm{cB}}=19,0 \%: 1-$ удельной теплоемкости с, Дж/(кг ×К); 2 - коэффициента теплопроводности $\lambda$, Вт/(м/К); 3 - коэффициента температуропроводности a, м $^{2} \mathrm{c}$

Figure 6 . The change in the thermophysical properties of cattle blood as a function of temperature, $\mathrm{K}$ at a solids content of $\mathrm{C}_{\mathrm{sv}}=19.0 \%$ : 1 - specific heat $\mathrm{c}, \mathrm{J} /(\mathrm{kg} \times \mathrm{K}) ; 2-$ coefficient of thermal conductivity $\lambda, \mathrm{W} /(\mathrm{m} / \mathrm{K}) ; 3-$ coefficient of thermal diffusivity a, $\mathrm{m}^{2} / \mathrm{s}$

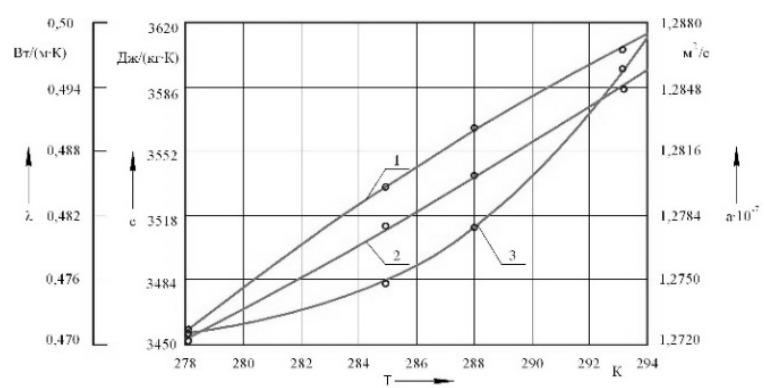

Рисунок 7. Изменение теплофизических свойств крови КРС в зависимости от температуры Т, К при содержании сухих веществ $\mathrm{C}_{\mathrm{cB}}=29,3 \%: 1-$ удельной теплоемкости с, Дж/(кг ×К); 2 - коэффициента теплопроводности $\lambda, \mathrm{BT} /(\mathrm{м} / \mathrm{K})$; 3 - коэффициента температуропроводности a, $\mathrm{m}^{2} / \mathrm{c}$

Figure 7. The change in the thermophysical properties of the blood of cattle as a function of temperature $\mathrm{T}, \mathrm{K}$ at a solids content of $\mathrm{Cs}=29.3 \%: 1$ - specific heat c, $\mathrm{J} /(\mathrm{kg} \times \mathrm{K})$; 2 - coefficient of thermal conductivity $\lambda, \mathrm{W} /(\mathrm{m} / \mathrm{K})$; 3 - coefficient of thermal diffusivity a, $\mathrm{m}^{2} / \mathrm{s}$

Как видно из рисунков 4-7 зависимости коэффициентов тепло и температуропроводности крови и сконцентрированной крови КРС от температуры имеют вид плавных кривых, монотонно возрастающих с повышением температуры. Вид кривых может быть объяснен изменениями в характере формирования водородных связей при переносе теплоты в жидких средах. При этом теплопроводность вызвана переносом энергии в результате перемещения молекул от одного слоя к другому без изменения последовательности расположения слоев вещества [5].

\section{Заключение}

Результаты выполненных исследований могут быть полезны при расчете процесса теплообмена при переработке и концентрировании крови КРС в вымораживающих или выпарных установках, при разработке технологии и аппаратурного оформления производства сгущенной крови, необходимой для получения незаменимых лекарственных препаратов антианемического действия, а также ряда пищевых продуктов, обогащенных белково-гемоглобинным комплексом [6]. 


\section{ЛИТЕРАТУРА}

1 Антипов С.Т., Овсянников В.Ю., Корчинский А.А. Исследование процесса охлаждения крови крупного рогатого скота // Вестник Воронежского государственного университета инженерных технологий. 2017. Т. 79. № 1 (71). С. 11-14.

2 Овсянников В.Ю. Концентрирование плазмы крови крупного рогатого скота вымораживанием // Мясная индустрия. 2013. № 7. С. 74-49.

3 Dieterich F., Boscolo W.R., Pacheco Bertoldo M.T., da Silva V.S.N. et al. Development and Characterization of Protein Hydrolysates Originated from Animal Agro Industrial Byproducts // J DairyVetAnimRes. 2014. №1(2). Р. 00012.

4 Арет В.А., Руднев С.Д. Реология и физико-механические свойства пищевых продуктов: учебное пособие. СПб.: ИЦ Интермедия, 2014. 246 с.

5 Steffen P., Verdier C., Wagner C. Quantification of depletion-induced adhesion of red blood cells // Physical Review Letters. 2013. № 110. P. 018102.

6 Tomaiuolo G., Lanotte L., Ghigliotti G., Misbah C. et al. Red blood cell clustering in poiseuillemicrocapillary flow // Physics of Fluids. 2012. № 24. P. 51903.

7 Щеглов Н.Г. Факторы, влияющие на величину касательных напряжений ньютоновских жидкостей при ламинарном движении // Хранение и переработка сельхозсырья. 2015. № 1. С. 9-11.

8 Herwaldt B., Linden J.V., Bosserman E. et al. Transfusion-associated babesiosis in the United States: A description of cases // AnnInternMed. 2012. № 155. P. 509-19.

9 Никифоров Ю.Б., Светлов Ю.В., Калошин Ю.А., Бузетти К.Д. Влияние объемной плотности и удельной теплоемкости пищевых продуктов на их эффективную теплопроводность // Хранение и переработка сельхозсырья. 2015. № 10. С. 18-22.

10 Успенская М.Е., Антипова Л.В., Ибрагимова 3.Р. Газданова Р.Ю. Получение кормовых добавок с использованием крови бройлеров и кавитационной обработки // Технологии пищевой и перерабатывающей промышленности АПК-продукты здорового питания. 2014. № 1. C. 22-26.

\section{СВЕДЕНИЯ ОБ АВТОРАХ}

Сергей Т. Антипов д.т.н., профессор, проректор по научной и инновационной деятельности, Воронежский государственный университет инженерных технологий, пр-т Революции, 19, г. Воронеж, 394036, Россия, ast@vsuet.ru

Виталий Ю. Овсянников к.т.н., доцент, кафедра машин и аппаратов пищевых производств, Воронежский государственный университет инженерных технологий, пр-т Революции, 19, г. Воронеж, 394036, Россия, ows2003@mail.ru

Александр А. Корчинский аспирант, кафедра машин и аппаратов пищевых производств, Воронежский государственный университет инженерных технологий, пр-т Революции, 19, г. Воронеж, 394036, Россия, 79192492267@ya.ru

Александр А. Смирных к.т.н., доцент, м, Воронежский государственный университет инженерных технологий, пр-т Революции, 19, г. Воронеж, 394036, Россия, uchebaa.a.smirnykh@mail.ru

\section{КРИТЕРИЙ АВТОРСТВА}

Все авторы в равной степени принимали участие в написании рукописи и несут ответственность за плагиат. КОНФЛИКТ ИНТЕРЕСОВ

Авторы заявляют об отсутствии конфликта интересов. ПОСТУПИЛА 01.07.2017 ПРИНЯТА В ПЕЧАТЬ 01.08.2017

\section{REFERENCES}

1 Antipov S.T., Ovsyannikov V. Yu., Korchinsky A.A. Investigation of the process of cooling blood of cattle. VestnikVoronezhskogogosudarstvennogouniversitetainzhenernyhtehnologij [Bulletin of Voronezh State University of Engineering Technologies], 2017. 79. no. 1 (71), pp. 11-14 (in Russian).

2 Ovsjannikov V. Ju. Concentration of blood plasma of cattle by freezing. Mjasnajaindustrija [Meat Industry], 2013. no 7. pp. 74-49 (in Russian).

3 Dieterich F., Boscolo W.R., Pacheco Bertoldo M.T., da Silva V.S.N. et al. Development and Characterization of Protein Hydrolysates Originated from Animal Agro Industrial Byproducts. J. DairyVetAnimRes. 2014. no. 1(2). pp. 00012.

4 Aret V.A, Rudnev S.D. Rheology and physical and mechanical properties of food: a textbook. [Reologija I fiziko-mehanicheskie svojstva pishhevyhproduktov: uchebnoeposobie] Saint-Petersburg, IC Intermedia, 2014. 246 p. (in Russian).

5 Steffen P., Verdier C., Wagner C. Quantification of depletion-induced adhesion of red blood cells. Physical Review Letters. 2013. no. 110. pp. 018102.

6 Tomaiuolo G., Lanotte L., Ghigliotti G., Misbah C. et al. Red blood cell clustering in poiseuillemicrocapillary flow. Physics of Fluids. 2012. no. 24. pp. 51903.

7 Shcheglov N.G. Factors affecting the magnitude of the tangential stresses of Newtonian liquids under laminar motion. Hranenie I pererabotka sel'hozsyr'ja [Storage and processing of agricultural raw materials], 2015, no 1, pp. 9-11 (in Russian).

8 Herwaldt B., Linden J.V., Bosserman E. et al. Transfusion-associated babesiosis in the United States: A description of cases. Ann Intern Med 2012. no. 155. pp. 509-19.

9 Nikiforov Yu.B., Svetlov Yu.V., Kaloshin Yu.A., Buzetti K.D. Influence of bulk density and specific heat of food products on their effective thermal conductivity. Hranenie I pererabotka sel'hozsyr'ja [Storage and processing of agricultural raw materials], 2015. no. 10. pp. 18-22 (in Russian).

10 Uspenskaya M.E., Antipova L.V., Ibragimova Z.R. Gazdanova R.Yu. Obtaining feed additives using broiler blood and cavitation treatment. Tehnologiipishhevojipererabatyvajushhejpromyshlennosti APK-produktyzdorovogopitanija. [Technologies of food and processing industry AIC-products of healthy nutrition] 2014. no. 1. pp. 22-26 (in Russian).

\section{INFORMATION ABOUT AUTHORS}

Sergei T. Antipov doctor of technical sciences, professor, vicerector of research and innovation, Voronezh state university of engineering technologies, Revolution Av., 19 Voronezh, 394036, Russia, ast@vsuet.ru

Vitaly Yu. Owsyannikov candidate of technical sciences, assistant professor, machines and equipment of food production department, Voronezh state university of engineering technologies, Revolution Av., 19 Voronezh, 394036, Russia, ows2003@mail.ru

Aleksandr A. Korchinskij candidate of economical sciences, engineer, machines and equipment of food production department, Voronezh state university of engineering technologies, Revolution Av., 19 Voronezh, 394036, Russia, 79192492267@ya.ru

Aleksandr A. Smyrnykh candidate of technical sciences, assistant professor, technology of fats, processes and devices of chemical and food productions department, Voronezh state university of engineering technologies, Revolution Av., 19 Voronezh, 394036, Russia, ucheba-a.a.smirnykh@mail.ru

\section{CONTRIBUTION}

All authors equally took part in writing the manuscript and are responsible for plagiarism.

CONFLICT OF INTEREST

The authors declare no conflict of interest. RECEIVED 7.1.2017 